\title{
The Formation Mechanism of Green Dairy Industry Chain from the Perspective of Green Sustainable Development
}

\author{
Hongli Chen $\mathbb{D}^{1,2}$ and Xiuli Liu $\mathbb{D}^{1,3}$ \\ ${ }^{1}$ University of Chinese Academy of Sciences, Beijing 100049, China \\ ${ }^{2}$ Xinjiang Tianshan Army Reclamation Co., Ltd, Xinjiang 832000, China \\ ${ }^{3}$ Academy of Mathematics and Systems Sciences Chinese Academy of Sciences, Beijing 100190, China
}

Correspondence should be addressed to Hongli Chen; chenhongli2050@sina.com

Received 15 March 2020; Accepted 16 April 2020; Published 11 May 2020

Guest Editor: Baogui Xin

Copyright (c) 2020 Hongli Chen and Xiuli Liu. This is an open access article distributed under the Creative Commons Attribution License, which permits unrestricted use, distribution, and reproduction in any medium, provided the original work is properly cited.

\begin{abstract}
By constructing an evolutionary game model of green dairy industry chain from the perspective of green sustainable development, this paper analyzed the evolution process of strategy selection of dairy farmers and dairy enterprises under the supervision of the government. The study found the following. (1) In the absence of supervision, even if the initial cooperation willingness of dairy farmers and dairy enterprises is strong, once the additional cost of their input of "green production" is less than the additional benefit, they will eventually choose noncooperative strategy. (2) In the case of government supervision, when the government punishment or subsidy is not strong enough, the strategic choice of dairy farmers and dairy enterprises will fluctuate repeatedly, and the game equilibrium cannot be reached. However, when the government punishments and subsidies are strong enough, dairy farmers and dairy enterprises will choose to cooperate in their own interests. At this time, government subsidies have a greater impact on the evolution of bilateral cooperation than government punishments. (3) The reduction of green production cost can promote the formation of the green dairy industry chain, which is conducive to the green dairy industry chain system to achieve an ideal equilibrium state.
\end{abstract}

\section{The Introduction}

The concept of "green development" which was put forward at the fifth Plenary Session of the 18th CPC Central Committee has been deeply rooted in people's hearts. Green development has become the theme of The Times. From the perspective of industrial transformation and upgrading, the green transformation of the entire industrial chain should also be an inevitable theme. The green industrial chain refers to promoting the green development of all links in the whole industrial value chain, realizing the benign interaction with nature and relevant groups in society, achieving the unity of short-term interests and long-term development, and realizing the sustainable development of the industry. With the support of the state for green industry, green supply chain will have a great development in the future. Dairy industry is a basic industry related to national economy and people's livelihood. The formation of the green dairy industry chain is conducive to the change of industrial model and the improvement of dairy product quality and safety. At present, China Mengniu diary and Yili Milk, as the first camp member of global dairy industry and the leader of China's dairy industry, have been committed to the development goal of "environmental protection" and "win-win" and have promoted the green and sustainable development of all links of the industrial chain with the mode of sustainable development.

Scholars have also conducted a multiangle and multilevel research on dairy industry, dairy industry chain, and green industry chain.

1.1. Dairy Products Quality and Safety Research. Economic research on food safety began in the 1960s [1], and people began to pay more attention to food safety after the 1980s. Lankveld [2] found that the quality of dairy products 
in Poland and other countries improved significantly after they joined the EU, which verified the effectiveness of the EU dairy supply chain. Dornon [3] put forward that the dairy processing industry was a vertically integrated industry, which should pay attention not only to food safety in the processing link of the supply chain but also to pasture. Cardoso et al. [4] pointed out that dairy enterprises and darelated professionals should educate dairy farmers on animal welfare because dairy farmers believed that production was more important than the welfare of calves. Noordhuizen, Koca et al. believed that the use of hazard analysis and the application of critical control points could effectively guarantee the quality and safety of dairy enterprises [5]. Sorge et al. [6] investigated the execution procedures of bovine tuberculosis control in 238 dairy farmers in Canada and found that communication and communication with dairy farmers could effectively improve disease control behaviors. Liu et al. [7] used the principle of quality control diagram to test standard samples of milk powder and found through experiments that it could improve the quality of monitored products. Wu et al. [8] determined the influencing factors of the intention to implement the comprehensive quality control behavior of dairy farmers by using the multiorder Logit model. The research shows that behavioral attitude, cooperative and coordinating attitude, and government encouragement and support are the surface direct factors. Zhang and Gong [9], based on the industrial chain perspective and discussion on dairy safety issues, put forward suggestions on strengthening the degree of integration, supervising the quality and safety of the supply chain, improving the benefit connection mechanism between enterprises and dairy farmers, and playing the supporting role of the government.

1.2. Dairy Industry Chain Research. The research on the dairy industry chain mainly focuses on how to improve the competitiveness of the industry chain and increase the value of the industry chain and the relationship between the main bodies of the industry chain. Bryndis and Martin [10], on the basis of the research on the dairy industry chain, considered to reduce the energy consumption in production by replacing milk powder with concentrated milk powder. Dries et al. [11] found through investigation of several countries in central and Eastern Europe that small dairy farms benefited from more cost and higher value market channels. Ding et al [12] studied whether the participation of federal, state, and local governments would affect the performance of the dairy industry chain. Based on the farmer survey, the determinants of market channel selection for small milk producers were analyzed and the effects of these market channel choices on farmers' income and technology adoption were studied. Nyokabi et al. [13], Kilelu et al. [14], and Gorton et al. [15] studied the multistakeholder relationship in the process of value chain appreciation of dairy products and its impact on value appreciation and industrial chain development.

\subsection{Study on the Green Development of Dairy Products.} The research on the green development of dairy products mainly focuses on the environmental management of dairy products production, supply chain management, and green infrastructure construction. Yawar and Kauppi [16] and Goesch et al. [17] pointed out the role of the government in the green development of dairy products through research on the environmental management practice of dairy production. Kirilova and Vaklieva-Bancheva [18], Powell et al. [19], Yazdani et al. and McWilliam and Balzarova [20, 21], Rajabian Tabesh et al. [22], and Shibin et al. [23, 24] put forward that the guiding and supervising role of the government is of great significance to promote the green and sustainable development of the whole dairy industry chain.

Relevant studies by domestic and foreign experts and scholars show that optimizing the behavior of subjects in the dairy industry chain, improving the cooperative relationship between subjects and giving full play to the "self-organizing" role of the dairy industry chain, and seeking green, healthy, and sustainable development are effective ways to solve the quality and safety problems of dairy products $[25,26]$. At present, although China and dairy companies attach great importance to the formation and development of green dairy industry chain, the effect of green dairy supply chain is not obvious. Due to the large number of subjects involved in the dairy industry chain, in addition to the uncertainty and complexity of the external factors affecting the formation of the green dairy industry chain, the balance of interests among the subjects is also the main factor affecting the formation of the green dairy industry chain. For example, for dairy farmers, green production requires higher production cost and production technology, which makes them pay more human, material, and financial resources. For dairy enterprises, it is not only necessary to supervise the raw milk materials provided by dairy farmers but also to innovate in technology. The high cost of green production for dairy farmers and dairy enterprises is the obstacle and resistance to the formation of green dairy industry chain. In order to effectively promote the formation of the green dairy industry chain, it is necessary for the government to guide, support, and supervise, so as to reduce the contrast between internalized costs and externalized benefits of green production for dairy farmers and dairy enterprises. Therefore, what are the influencing factors of cooperation between dairy farmers and dairy enterprises under government supervision? What is the mechanism of government guidance for the formation of the green dairy industry chain? How can faster and more efficient design promote the formation of the green industrial chain? These problems are of great significance for vigorously promoting the cooperation among the main players of the green dairy industry chain and enhancing the value of the green industry chain. Based on this, this paper established an evolutionary game model for the sustainable development of the green dairy industry chain from the perspective of government supervision, which considered the influences of the government's penalty and reward policies on the behavior strategy choices of main bodies involved in the dairy industry. A sustainable green dairy industry chain formation mechanism was proposed and further discussed by means of simulation study. 


\section{Model Construction}

Game refers to the process in which each player chooses his or her own strategy (action) based on the information he or she has mastered, so as to realize the maximization of benefits and the minimization of risks and costs $[27,28]$. Evolutionary game theory was first applied to analyze the stability of a trait against variation in the evolution of biological population [29,30]. Later, economists introduced evolutionary game into economics and management [31-33]. Evolutionary game theory is a method that combines game and dynamic evolution, which can study the stable structure of the game system and the strategy selection process of the players by means of introducing dynamic mechanism. The basic idea is that, in a group of a certain size, game players are not super rational players, and it is impossible to find the optimal equilibrium point in every game, but repeated game can achieve equilibrium through trial and correction. Thus, the best strategy for game players is to imitate and improve the strategies in the past. Through long-term imitation and improvement, all game players will tend to choose a certain stable strategy.

"Green" products are based on the ecological environment, with strict product quality requirements and core competitiveness. The green dairy industry is based on green food, and more emphasis is placed on the production and consumption of nonpolluting dairy products with high nutrition, high quality, and environmental ecology on the basis of safety. The green dairy industry chain is based on the entire dairy industry chain, starting from the source of the industry chain, until the sale of green dairy products to the end consumer. Therefore, it is necessary to supervise each production process of green dairy products to ensure green milk. The whole process of product control is the basic guarantee for realizing the food safety of dairy products.

At the early stage of green dairy industry chain formation, there are contradiction between dairy farmers and dairy enterprises, enterprises' profits and social responsibility, and short-term economic profit and long-term sustainable development. Besides, resources endowment and the understanding of the green dairy industry chain make it difficult for the parties to achieve their optimal strategies. Continuous trial and error correction, learning, and improvement are needed to form evolutionary stable strategy of a game. Due to the complex game relationship involved in the green dairy industry chain and various factors affecting strategy selection, this paper first conduced a literature retrieval on the green dairy industry chain formation, which shows that the basic benefits of dairy farmers and milk enterprises, green input costs, double income from the green production, and punishment for nongreen production are the core factors affecting the formation of the green dairy industry chain [34-37]. Therefore, based on the existing research results, this paper, taking these main factors as the main parameters, constructed an evolutionary game model of the formation mechanism of the green dairy industry chain from the perspective of sustainable development.

\subsection{Model Assumptions}

Hypothesis 1. In the process of the green dairy industry chain formation, there are many stakeholders involved. In this paper, dairy farmers and dairy enterprises are studied as main game players.

Hypothesis 2. It is assumed that, in the process of the green dairy industry chain formation, dairy farmers and dairy enterprises are bounded rational, the strategy selection is characterized with inertia, the players make decisions based on existing strategies, and their ultimate purpose is to maximize their own interests.

Hypothesis 3. In the early stage of the game, the proportion of dairy farmers choosing "green production" and "nongreen production" are $x$ and $1-x$, respectively. The proportion of dairy enterprises choosing "green production" and "nongreen production" are $y$ and $1-y$, respectively.

2.2. Model Symbol Description. In this paper, the hypothesis of profit and loss variables and related parameters of the interest game players are set as follows.

The basic income of the dairy farmers in the dairy industry chain is $R_{1}$. Owing to the fact that the production needs to input a certain amount of human, material, and financial resources, the resulting cost is $C_{1}$. When dairy farmers choose green production, they need to invest additional costs in technology, equipment, and other aspects $\Delta C_{1}$. If enterprises also choose green production at the same time, dairy farmers will get additional benefits $\Delta R_{1}$. If the enterprise chooses green production, the enterprise can examine the behavioral decisions of the dairy farmers through the milk source tracing system. If the dairy farmers do not adopt green production, they will be compensated for violating the cooperation agreement between the two parties, which is set as $\Pi$.

The basic income of dairy enterprises in the industrial chain is $R_{2}$, and the input cost in the production process of dairy products is $C_{2}$. When dairy enterprises choose green production and dairy farmers do not choose green production, the enterprises need to invest additional costs $\Delta / C_{2}$ in technology and equipment, etc. If the dairy farmers choose green production, the additional costs that the enterprises need to invest are $\Delta C_{2}$. Obviously, there is $\Delta C_{2}>\Delta^{\prime} C_{2}$. When dairy enterprises choose green production, they will gain additional benefits $\Delta R_{2}$ due to the recognition of green food by consumers.

The game profit and loss matrix of the two under different strategies is shown in Table 1.

\section{Evolutionary Game Model Construction}

3.1. Construction of Replicated Dynamic Equations. Based on the abovementioned assumptions and payment matrix, dairy farmers and dairy products companies will obtain corresponding benefits by adopting different strategies and can establish a replication dynamic system. 
TABLE 1: Game income matrix of dairy farmers and dairy production enterprises.

\begin{tabular}{cccc}
\hline & & \multicolumn{2}{c}{ Dairy production enterprises } \\
& & Green production $(y)$ & Nongreen production $(1-y)$ \\
\hline \multirow{2}{*}{ Diary farmers } & Green production $(x)$ & $R_{1}-C_{1}+\Delta R_{1}-\Delta C_{1}, R_{2}-C_{2}+\Delta R_{2}-\Delta C_{2}$ & $R_{1}-C_{1}-\Delta C_{1}, R_{2}-C_{2}$ \\
& Nongreen production $(1-x)$ & $R_{1}-C_{1}-\Pi, R_{2}-C_{2}+\Delta R_{2}-\Delta / C_{2}+\Pi$ & $R_{1}-C_{1}, R_{2}-C_{2}$ \\
\hline
\end{tabular}

According to Malthusian equation in evolutionary game theory, in the process of green development of the dairy industry chain, the expected benefits of dairy farmers choosing "green production" strategy and "nongreen production" are $E_{1}^{1}$ and $E_{1}^{2}$, respectively:

$$
\begin{aligned}
& E_{1}^{1}=y\left(R_{1}-C_{1}+\Delta R_{1}-\Delta C_{1}\right)+(1-y)\left(R_{1}-C_{1}-\Delta C_{1}\right), \\
& E_{1}^{2}=y\left(R_{1}-C_{1}-\Pi\right)+(1-y)\left(R_{1}-C_{1}\right),
\end{aligned}
$$

where $E_{1}^{1}$ and $E_{1}^{2}$ are actually the gains obtained by dairy farmers when they adopt different strategies, so the average benefits of the mixed strategy of "green production" and "nongreen production" selected by dairy farmers are as $\bar{E}_{1}$ :

$$
\bar{E}_{1}=x E_{1}^{1}+(1-x) E_{1}^{2} \text {. }
$$

Therefore, the replication dynamic equation that dairy farmers choose "green production" strategy is as follows:

$$
F(x)=\frac{\mathrm{d} x}{\mathrm{~d} t}=x\left(E_{1}^{1}-\bar{E}_{1}\right)=x(1-x)\left[y\left(\Delta R_{1}+\Pi\right)-\Delta C_{1}\right] .
$$

Similarly, the expected benefits of dairy enterprises choosing "green production" and "nongreen production" are $E_{2}^{1}$ and $E_{2}^{2}$ :

$$
\begin{aligned}
E_{2}^{1}= & x\left(R_{2}-C_{2}+\Delta R_{2}-\Delta C_{2}\right)+(1-x) \\
& \left(R_{2}-C_{2}+\Delta R_{2}-\Delta \prime C_{2}+\Pi\right), \\
E_{2}^{2}= & x\left(R_{2}-C_{2}\right)+(1-x)\left(R_{2}-C_{2}\right) .
\end{aligned}
$$

The average benefits of dairy enterprises' mixed strategies of "green production" and "nongreen production" are $\bar{E}_{2}$ :

$$
\bar{E}_{2}=y E_{2}^{1}+(1-y) E_{2}^{2} \text {. }
$$

Therefore, the replication dynamic equation that dairy enterprises choose "green production" are as follows:

$$
\begin{aligned}
D(y)= & \frac{\mathrm{d} y}{\mathrm{~d} t}=y\left(E_{2}^{1}-\bar{E}_{2}\right)=y(1-y) \\
& \cdot\left[x\left(\Delta^{\prime} C_{2}-\Delta C_{2}-\Pi\right)+\Delta R_{2}-\Delta^{\prime} C_{2}+\Pi\right] .
\end{aligned}
$$

The two-dimensional dynamic system (I) of the replication dynamic equation involved dairy farmers and milk enterprise can be gotten in accordance with equations (3) and (6).

From the abovementioned analysis, it can be seen that only when the income and payment cost of dairy farmers and dairy product enterprises adopting "noncooperation" are less than the revenue and payment cost of cooperation between the two parties, both parties of the rational person will adopt the "cooperation" strategy At this time, $x=1$ and $y=1$, respectively, indicate that the dairy farmers and dairy products companies choose the "green production" behavior strategy.

\subsection{Stability Analysis of Equilibrium Point}

Proposition 1. If the dairy farmers and dairy enterprises constitute a two-dimensional dynamic system (I), there are $2^{2}=4$ group strategy equilibrium points, namely, $(1,1),(1,0)$, $(0,1)$, and $(0,0)$. At the same time, there should be an equilibrium point of a mixed strategy, which satisfies $\left(x^{*}, y^{*}\right), x^{*} \in[0,1]$, and $y^{*} \in[0,1]$ :

$$
\begin{aligned}
& x^{*}=\frac{\Delta R_{2}-\Delta^{\prime} C_{2}+\Pi}{\Delta C_{2}-\Delta^{\prime} C_{2}+\Pi}=M, \\
& y^{*}=\frac{\Delta C_{1}}{\Delta R_{1}+\Pi}=N .
\end{aligned}
$$

Proof. For two-dimensional dynamic system (I), when $x=0$ or $x=1$ and $y=0$ or $y=1$, there is $F(x)=0$ and $D(y)=0$. Therefore, $(1,1),(1,0),(0,1)$, and $(0,0)$ are the equilibrium points of the system. When $0<x<1$ and $0<y<1$, if $y\left(\Delta R_{1}+\right.$ П) $-\Delta C_{1}=0 \quad$ and $\quad x\left(\Delta^{\prime} C_{2}-\Delta C_{2}-\Pi\right)+\Delta R_{2}-\Delta^{\prime} C_{2}+$ $\Pi=0$, then there is $F(x)=0, D(y)=0$. Solve the system of equation (8) and obtain that $\left(x^{*}, y^{*}\right)$ is the possible equilibrium point of two-dimensional dynamic system (I):

$$
\left\{\begin{array}{r}
y\left(\Delta R_{1}+\Pi\right)-\Delta C_{1}=0, \\
x\left(\Delta^{\prime} C_{2}-\Delta C_{2}-\Pi\right)+\Delta R_{2}-\Delta^{\prime} C_{2}+\Pi=0 .
\end{array}\right.
$$

According to [27], the equilibrium of a two-dimensional dynamic system (I) can be defined as an evolutionarily stable strategy (ESS for short) only through the stability test, which means the local stability of Jacobian matrix can be used to judge the stability of the equilibrium.

The Jacobian Matrix of the system is as below:

$$
J=\left[\begin{array}{ll}
\frac{\partial G(x)}{\partial x} & \frac{\partial G(x)}{\partial y} \\
\frac{\partial F(y)}{\partial x} & \frac{\partial F(y)}{\partial y}
\end{array}\right]=\left[\begin{array}{ll}
a_{11} & a_{12} \\
a_{21} & a_{22}
\end{array}\right],
$$

where 


$$
\begin{aligned}
& a_{11}=(1-2 x)\left[y\left(\Delta R_{1}+\Pi\right)-\Delta C_{1}\right], \\
& a_{12}=x(1-x)\left(\Delta R_{1}+\Pi\right), \\
& a_{21}=y(1-y)\left(\Delta^{\prime} C_{2}-\Delta C_{2}-\Pi\right), \\
& a_{22}=(1-2 y)\left[x\left(\Delta^{\prime} C_{2}-\Delta C_{2}-\Pi\right)+\Delta R_{2}-\Delta^{\prime} C_{2}+\Pi\right] .
\end{aligned}
$$

If the following two conditions are satisfied, the equilibrium point of the replication dynamic equation is the evolutionary stable strategy (ESS):

(1) $\operatorname{tr} J=a_{11}+a_{22}<0$ (trace condition)

(2) $\operatorname{det} J=\left|\begin{array}{ll}a_{11} & a_{12} \\ a_{21} & a_{22}\end{array}\right|=a_{11} a_{22}-a_{12} a_{21}>0$ (Jacobian condition)

From the abovementioned calculation results, it can be seen that there is $a_{11}+a_{22}=0$ at the local equilibrium point $(M, N)$, which does not conform to the equilibrium point. Therefore, $(M, N)$ is definitely not the system's evolutionary stable strategy (ESS). As for the remaining four equilibrium points, according to the determinant and trace values of the Jacobian matrix $J$, the local stability of the equilibrium points can be judged. The results are shown in Table 2.

\section{Result Analysis}

According to ESS analysis of Table 2 and the replicated dynamic equation, it can be known as follows.

Proposition 2. When $\Delta R_{2}-\Delta^{\prime} C_{2}+\Pi<0$, since $-\Delta C_{1}<0$, the evolutionary stable strategy (ESS) of two-dimensional dynamical system (I) is $(0,0)$.

Proof. It can be judged according to the determinant and trace of Jacobian.

This shows that, in the process of the formation of the green dairy industry chain, the sum of the extra income $\Delta R_{2}$ obtained by the dairy enterprises when they choose green production and the cost $\Pi$ fined by the dairy farmers when they do not choose green production is less than the extra cost $\Delta / C_{2}$ required by the enterprises when they choose green production, and the enterprises will choose noncooperative strategy. At the same time, if dairy farmers choose green production, they will need to invest additional costs $\Delta C_{1}$. At this time, dairy enterprises choose noncooperative strategy, and dairy farmers have no additional benefits, so they will choose noncooperative strategy. In summary, both the dairy enterprises and the dairy farmers choose nongreen production. Therefore, $(0,0)$ is the stable point of the system evolution.

Proposition 3. If $\Delta R_{1}+\Pi-\Delta C_{1}<0$ and $\Delta R_{2}-\Delta^{\prime} C_{2}+$ $\Pi>0$, the evolutionary stable strategy (ESS) of two-dimensional dynamical system $(I)$ is $(0,1)$.

Proof. It can be judged according to the determinant and trace of Jacobian.
TABLE 2: Determinant values and traces of local equilibrium points.

\begin{tabular}{lcccc}
\hline & $a_{11}$ & $a_{12}$ & $a_{21}$ & $a_{22}$ \\
\hline$(0,0)$ & $-\Delta C_{1}$ & 0 & 0 & $\Delta R_{2}-\Delta^{\prime} C_{2}+\Pi$ \\
$(0,1)$ & $\Delta R_{1}+\Pi-\Delta C_{1}$ & 0 & 0 & $-\left[\Delta R_{2}-\Delta^{\prime} C_{2}+\Pi\right]$ \\
$(1,0)$ & $\Delta C_{1}$ & 0 & 0 & $\Delta R_{2}-\Delta C_{2}$ \\
$(1,1)$ & $-\left[\Delta R_{1}+\Pi-\Delta C_{1}\right]$ & 0 & 0 & $-\left[\Delta R_{2}-\Delta C_{2}\right]$ \\
$\left(x^{*}, y^{*}\right)$ & 0 & $\mathrm{M}$ & $\mathrm{N}$ & 0 \\
\hline
\end{tabular}

This means that, in the process of formation of the green dairy industry chain, when the sum of extra income $\Delta R_{1}$ gained by the green production and opportunity cost $\Pi$ that enterprises choose nongreen enterprises is less than the extra cost of investment $\Delta C_{1}$ that dairy farmers choose green production, farmers will choose noncooperative strategy for their own benefit maximization. At the same time, dairy enterprises will choose cooperation because the overall benefit is greater than the cost. In other words, when dairy farmers choose green production, their own interests will be damaged, while dairy enterprises choose green production, and their own profits will increase. Therefore, both sides of the game ultimately choose nongreen production strategy and green production strategy. Therefore, $(0,1)$ is the stable point of the system evolution.

Proposition 4. Two-dimensional dynamical system (I) does not have an evolutionary stable strategy (ESS) of $(1,0)$.

Proof. It can be judged according to the determinant and trace of Jacobian.

This shows that when dairy enterprises do not choose green production, dairy farmers will choose green production because there is no supervision of dairy enterprises. In other words, if there is no external force imposed, dairy farmers have no motivation to carry out green production because it requires extra investment but does not get additional benefits. As a rational person, it will definitely choose nongreen production, so there is no ESS of $(1,0)$ for the two-dimensional dynamical system.

Proposition 5. If $\Delta R_{1}+\Pi-\Delta C_{1}>0$ and $\Delta R_{2}-\Delta C_{2}>0$, the evolutionary stable strategy (ESS) of two-dimensional dynamical system (I) is $(1,1)$.

It can be judged according to the determinant and trace of Jacobian.

This shows that, in the process of green dairy industry chain formation, when both dairy farmers and dairy enterprises choose green production, their overall benefits are greater than their costs, and they will eventually choose cooperation strategy. In other words, at this time, both rational parties have maximized interests and they tend to adopt cooperative strategies. Therefore, $(1,1)$ is the stable point of the evolution of the system.

It can be seen from the abovementioned analysis that if the extra input cost of dairy farmers and dairy enterprises does not get a large profit in the process of forming the green dairy industry chain, or the input cost is far greater than the profit, the rational people will not choose green production. Due to the frequent occurrence of agricultural products and 
food safety incidents in recent years, the state has continuously strengthened the supervision of agricultural products and food, and the formation of the green dairy industry chain is also imminent. Therefore, in the process of forming the green dairy industry chain, the government's reward and punishment mechanism will play a huge role. It is assumed that the government can ensure its ability to inspect green production in the process of forming the green dairy industry chain, and it will not cover up the noncooperative strategy of the other party due to corruption and bribery.

It is assumed that, in the process of the formation of the green dairy industry chain, the government will punish dairy farmers or dairy enterprises once they are found to be uncooperative and provide policy subsidies to dairy farmers or dairy enterprises that have actively cooperated with them. In this case, the probability that government agencies supervise are $z$ and $1-z$, and the government, dairy farmers, and dairy enterprises are rational people.

In this paper, the government is regarded as a game player and its main income is tax and fines for noncooperative game players. Moreover, when both dairy farmers and dairy enterprises choose green production, the green development benefits of the government will be promoted, but the cooperative game players need to be rewarded. Therefore, the profit and loss analysis of the government is as follows: the government rewards to dairy farmers and dairy enterprises for choosing green production are $G_{1}$ and $G_{2}$, respectively, and the fines for dairy farmers and dairy enterprises for choosing green production are $g_{1}$ and $g_{2}$, respectively. The investment the government pays for supervising the formation of the green dairy industry chain is $C_{3}$, basic revenue from government taxation is $R_{3}$, and the benefits obtained from dairy farmers and dairy enterprises to choose green production are $\Delta R_{3}$ and $\Delta^{\prime} R_{3}$, respectively. Therefore, the revenue matrix of the government being a game player in the process of forming the green dairy industry chain is shown in Table 3 below.

The income matrix of the government in the formation process of the green dairy industry chain can be calculated according to Table 3 . In the process of the green development of the dairy industry chain, the expected benefits of the government choosing supervision strategy and nonsupervision strategy are $E_{3}^{1}$ and $E_{3}^{2}$, respectively:

$$
\begin{aligned}
E_{3}^{1}= & {\left[x y\left(R_{3}+\Delta R_{3}+\Delta^{\prime} R_{3}-G_{1}-G_{2}-C_{3}\right)+x(1-y)\left(R_{3}+\Delta R_{3}+g_{2}-C_{3}-G_{1}\right)\right] } \\
& +\left[(1-x) y\left(R_{3}+\Delta^{\prime} R_{3}+g_{1}-C_{3}-G_{2}\right)+(1-x)(1-y)\left(R_{3}-C_{3}+g_{1}+g_{2}\right)\right] \\
E_{3}^{2}= & {\left[x y\left(R_{3}+\Delta R_{3}+\Delta^{\prime} R_{3}\right)+x(1-y)\left(R_{3}+\Delta R_{3}\right)\right]+\left[(1-x) y\left(R_{3}+\Delta \prime R_{3}\right)+(1-x)(1-y) R_{3}\right] . }
\end{aligned}
$$

The average benefits of the mixed strategy of supervision strategy and nonsupervision strategy chosen by the government are as follows:

$$
\bar{E}_{3}=z E_{3}^{1}+(1-z) E_{3}^{2} \text {. }
$$

Therefore, the replication dynamic equation that the government chooses supervision strategy is as follows:

$$
\begin{aligned}
G(x)= & \frac{\mathrm{d} z}{\mathrm{~d} t}=z\left(E_{3}^{1}-\bar{E}_{3}\right)=z(1-z)\left[-x\left(G_{1}-g_{1}\right)\right. \\
& \left.-y\left(G_{2}-g_{2}\right)+g_{1}+g_{2}\right] .
\end{aligned}
$$

Under the government's reward and punishment mechanism, the replication dynamic equation of dairy farmers and dairy enterprises will also change during the formation of the green dairy industry chain, which is shown as follows:

$$
\begin{aligned}
F_{1}(x)= & \frac{\mathrm{d} x}{\mathrm{~d} t}=x(1-x)\left[y\left(\Delta R_{1}+\Pi\right)+z G_{1}+y z g_{2}\right. \\
& \left.+(1-y) z g_{1}-\Delta C_{1}\right], \\
D_{1}(y)= & \frac{\mathrm{d} y}{\mathrm{~d} t}=y(1-y)\left[x\left(\Delta^{\prime} C_{2}-\Delta C_{2}-\Pi\right)\right. \\
& \left.+z G_{2}+x z g_{1}+(1-x) z g_{2}+\Delta R_{2}-\Delta^{\prime} C_{2}+\Pi\right] .
\end{aligned}
$$

In the process of forming the green dairy industry chain, the government rewards and penalizes dairy farmers and dairy enterprises, which can reduce the volatility of the game and accelerate the speed of all parties to reach the equilibrium state. According to the basic nature of the evolutionary game, $\left(x^{*}, y^{*}, z^{*}\right)$ is substituted into equations (13)-(15). When $F_{1}^{\prime}(x)<0, D_{1}^{\prime}(y)<0, G(z)<0$, $\left(x^{*}, y^{*}, z^{*}\right)$ is the stable strategy of dairy farmers, dairy enterprises, and the government under the multiplayer game formed by the green dairy industry chain. Since the government plays the role of supervision and support, this paper only analyzes the gradual stability of dairy farmers and dairy enterprises in the industrial chain, and the results are as follows.

\subsection{Progressive Stability Analysis of Dairy Farmers}

(1) If $y\left(\Delta R_{1}+\Pi\right)+z G_{1}+y z g_{2}+(1-y) z g_{1}-\Delta C_{1}=0$, then there is $F_{1}(x) \equiv 0$, which means the strategy selection of dairy farmers is in a stable state in the process of forming the green dairy industry chain, that is, the proportion of dairy farmers' strategy selection will not change with the passing of time.

(2) If $y\left(\Delta R_{1}+\Pi\right)+z G_{1}+y z g_{2}+(1-y) z g_{1}-\Delta C_{1}>0$, let $F_{1}(x)=0$, then $x=0$ and $x=1$ are two stable points of $x$. $F_{1}^{\prime}(x)=(1-2 x)\left[y\left(\Delta R_{1}+\Pi\right)+z G_{1}+\right.$ 
TABLE 3: The income matrix of the government in the forming process of the green dairy industry chain.

\begin{tabular}{|c|c|c|c|}
\hline & \multicolumn{2}{|c|}{ Governments } \\
\hline & & Supervising $(z)$ & $\begin{array}{l}\text { Nonsupervising } \\
\quad(1-z)\end{array}$ \\
\hline \multirow{4}{*}{$\begin{array}{l}\text { Strategy choices of dairy } \\
\text { enterprises and dairy } \\
\text { farmers }\end{array}$} & $\begin{array}{l}\text { Both parties have chosen cooperative strategies } \\
\qquad(x, y)\end{array}$ & $R_{3}+\Delta R_{3}+\Delta^{\prime} R_{3}-G_{1}-G_{2}-C_{3}$ & $R_{3}+\Delta R_{3}+\Delta / R_{3}$ \\
\hline & $\begin{array}{l}\text { Dairy farmers and dairy enterprises choose } \\
\text { cooperative strategy and noncooperative strategy } \\
\qquad(x, 1-y)\end{array}$ & $R_{3}+\Delta R_{3}+g_{2}-C_{3}-G_{1}$ & $R_{3}+\Delta R_{3}$ \\
\hline & $\begin{array}{l}\text { Dairy farmers and dairy enterprises choose } \\
\text { noncooperative strategy and cooperative strategy } \\
\qquad(1-x, y)\end{array}$ & $R_{3}+\Delta^{\prime} R_{3}+g_{1}-C_{3}-G_{2}$ & $R_{3}+\Delta^{\prime} R_{3}$ \\
\hline & $\begin{array}{l}\text { Both parties have chosen noncooperative strategies } \\
\qquad(1-x, 1-y)\end{array}$ & $R_{3}-C_{3}+g_{1}+g_{2}$ & $R_{3}$ \\
\hline
\end{tabular}

$\left.y z g_{2}+(1-y) z g_{1}-\Delta C_{1}\right]$, and then there is $F_{1}^{\prime}(0)>0$ and $F_{1}^{\prime}(1)<0$, so $x=1$ is the balance point of dairy farmers' strategy. It shows that extra profits $\Delta R_{1}$ and government subsidies $G_{1}$ obtained by the dairy farmers when they choose green production, the opportunity cost $g_{1}$ and $g_{2}$ and $\Pi$ of being fined when they choose green production, and the extra cost $\Delta C_{1}$ of investment required by the dairy farmers when they choose green production are all key factors that affect the strategy selection of dairy farmers. At this time, subsidies for the green dairy industry chain under government supervision and penalties for noncooperation of dairy farmers and dairy enterprises accelerate the emergence of cooperative behaviors of dairy farmers. Therefore, government supervision is of great significance to the formation of cooperative behaviors of dairy farmers in the green dairy industry chain.

(3) Similarly, if $y\left(\Delta R_{1}+\Pi\right)+z G_{1}+y z g_{2}+(1-y) z g_{1}-$ $\Delta C_{1}<0$, then $F_{1}^{\prime}(0)<0$ and $F_{1}^{\prime}(1)>0$, so $x=0$ is the balance point of dairy farmers' selection strategy. This shows that once the sum of the benefits of green production (including additional benefits and government incentives) and the opportunity cost of noncooperation is smaller than the additional cost of green production, the dairy farmers will choose noncooperative strategy because the input cost of green production is too high. Therefore, in the process of forming the green dairy industry chain, the government and dairy enterprises need not only supervise the dairy farmers but also provide support for green production technology and equipment.

\subsection{Progressive Stability Analysis of Dairy Enterprises}

(1) If $x\left(\Delta^{\prime} C_{2}-\Delta C_{2}-\Pi\right)+z G_{2}+x z g_{1}+(1-x) z g_{2}+$ $\Delta R_{2}-\Delta^{\prime} C_{2}+\Pi=0$, then there is $D_{1}^{\prime}(y) \equiv 0$, which means the strategic choice of dairy enterprises is a stable state, that is, the proportion of dairy industry strategic choice will not change with the passage of time.
(2) If $x\left(\Delta^{\prime} C_{2}-\Delta C_{2}-\Pi\right)+z G_{2}+x z g_{1}+(1-x) z g_{2}+$ $\Delta R_{2}-\Delta^{\prime} C_{2}+\Pi>0$, let $D_{1}(y)=0$, then $y=0$ and $y=1$ are two stable points of $y$. There is $D_{1}^{\prime}(y)=$ $(1-2 y)\left[x\left(\Delta^{\prime} C_{2}-\Delta C_{2}-\Pi\right)+z G_{2}+x z g_{1}+(1-x)\right.$ $\left.z g_{2}+\Delta R_{2}-\Delta^{\prime} C_{2}+\Pi\right], F_{2}^{\prime}(0)>0$, and $F_{2}^{\prime}(1)<0$, so $y=1$ is the stable points of diary enterprises' strategies. This shows that the extra income $\Delta R_{2}$ when the dairy enterprises choose the green production, the government's penalty $\Pi$ and subsidy $G_{2}$, the opportunity cost when the dairy enterprises choose green production and nongreen production $g_{1}$ and $g_{2}$, and the additional cost of dairy companies when the dairy farmers choose cooperative strategy and noncooperative strategy $\Delta / C_{2}$ and $\Delta C_{2}$ are the key factors influencing the dairy products enterprise strategy choice. Similarly, subsidies for the green dairy industry chain under government supervision and penalties for noncooperation of dairy farmers and dairy enterprises accelerate the generation of cooperative behaviors of dairy enterprises. Therefore, government supervision is of great significance to the formation of cooperative behaviors of dairy enterprises in the green dairy industry chain.

(3) Similarly, if $x\left(\Delta^{\prime} C_{2}-\Delta C_{2}-\Pi\right)+z G_{2}+x z g_{1}+$ $(1-x) z g_{2}+\Delta R_{2}-\Delta^{\prime} C_{2}+\Pi<0$, then there is $F_{1}^{\prime}(0)<0$ and $F_{1}^{\prime}(1)>0$, so $x=0$ is the balance point of dairy enterprises' selection strategy. This shows that the sum of the benefits the dairy enterprises choose green production (including the additional income and penalties and rewards from the governments) and the opportunity cost when the dairy enterprises choose noncooperative strategy is less than the additional expected cost $x \Delta C_{2}+(1-x) \Delta^{\prime} C_{2}$, and dairy companies will choose noncooperative strategies due to too high production cost. Therefore, in addition to government supervision, the behavior of dairy farmers at the initial stage of the industrial chain also has a huge impact on the behavior of dairy enterprises in the process of the formation of the green dairy industry chain.

All in all, the government can increase the cooperation income of dairy farmers and enterprises through subsidies 
and can also increase the noncooperative opportunity cost through penalties, so as to supervise and guide the formation of the green supply chain, and eventually realize the sustainable development of the dairy industry chain.

\section{Numerical Simulation}

Based on the analysis of the formation of green dairy industry chain under the supervision of the government, this paper compared the behavioral strategies of dairy farmers and dairy enterprises with or without government rewards and punishments to choose the evolutionary path and discussed the impact of the change of green production cost on the formation of the green dairy industry chain. Firstly, it is assumed that, in the early stage of the green dairy industry chain, dairy farmers, and dairy enterprises finally failed to reach cooperation intention, that is, ESS is $(0,0)$, at which time the parameters meet $\Delta R_{2}-\Delta / C_{2}+\Pi<0$. It is assumed that the value of relevant parameters in the game matrix is $\Delta R_{1}=\Delta R_{2}=1, \Delta / C_{2}=3, \Pi=0.5, \Delta C_{1}=1.5$, and $\Delta C_{2}=2$. Based on the abovementioned parameters, it is assumed that at the beginning of the green dairy industry chain, dairy farmers and dairy enterprises have a strong desire to cooperate, that is, at the beginning $x=y=0.9$. Government rewards and punishments, as well as the influence of changes in green production costs on the behavioral strategies of dairy farmers and dairy enterprises are simulated below.

\subsection{The Impact of Government Subsidies on the Formation of} Green Dairy Industry Chain. As shown in Figure 1, when there is no government subsidies, even if the initial willingness of dairy farmers and dairy enterprises to cooperate is strong, after a certain period of game learning, they will choose noncooperative because the income is less than the input. When the government intends to promote the formation of the green dairy industry chain, it can be obtained from the evolutionary game dynamics system that the critical point of dairy farmers for government's rewards is $G_{1}=0.15$ and the critical point of dairy enterprises is $G_{2}=1.05$. That is to say, when the government reward is higher than the critical point, dairy farmers and dairy enterprises will choose cooperative strategies. If one critical point is reached, assuming government subsidies $G_{1}=G_{2}=0.7$, dairy farmers and dairy enterprises will maximize their own interests and choose strategies that fluctuate between $(0,1)$ in the learning process of evolutionary game, eventually leading to the failure of both parties to reach a stable equilibrium state (as shown in Figure 2).

Only when the government subsidy is greater than the critical point, if $G_{1}=1.5$ and $G_{2}=2$, then dairy farmers and dairy enterprises will choose green production strategy. At this time, the dairy farmers and dairy enterprises can take the initiative to gain high net benefits from green production, which are also the results of continuous learning of dairy farmers and dairy companies. Therefore, it can be concluded that government subsidies can effectively promote green production of dairy farmers and dairy enterprises, promote

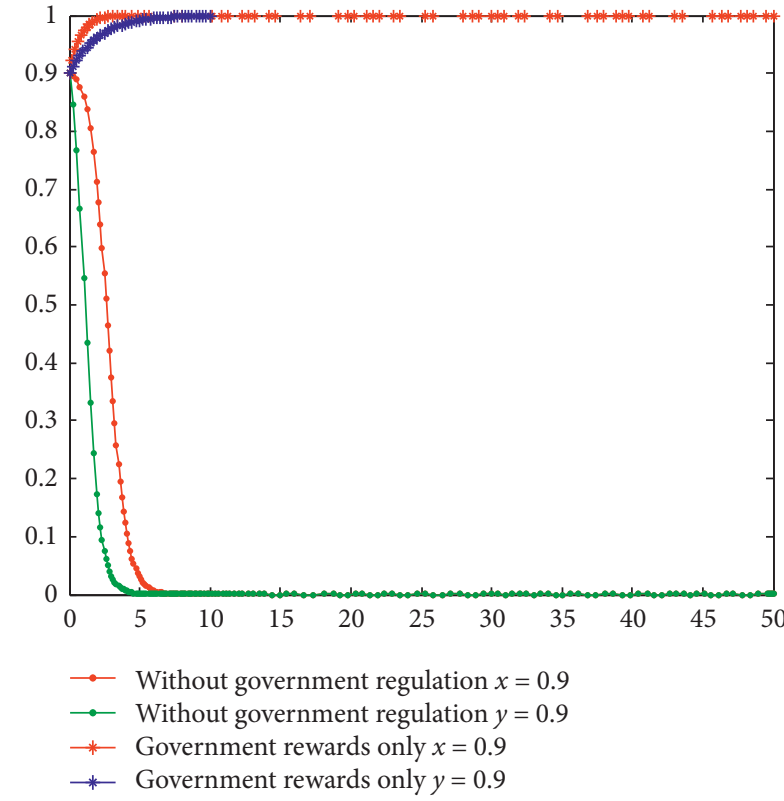

FIGURE 1: Influence of government subsidies on the formation of the green dairy industry chain.

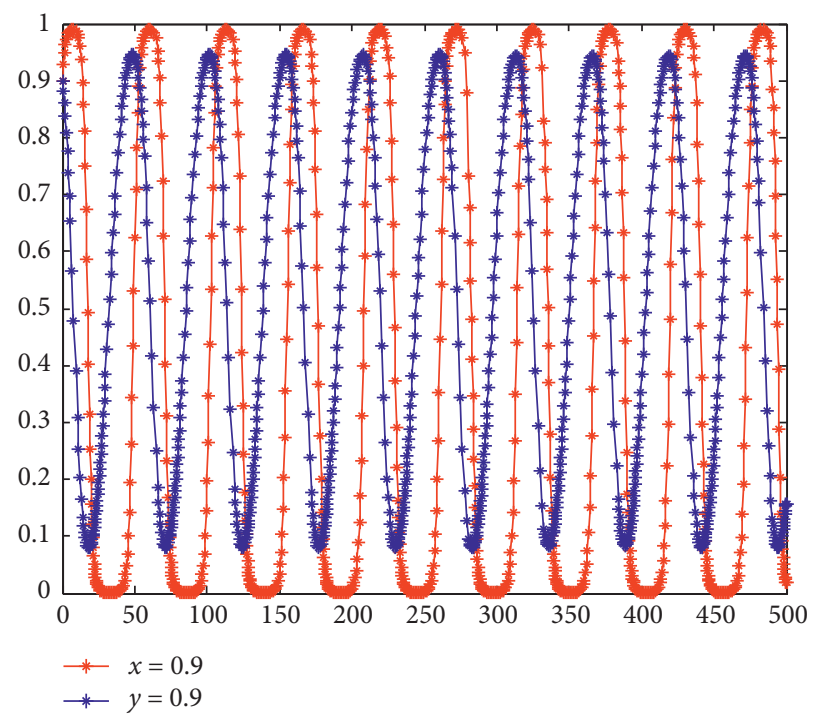

FIGURE 2: Influence of critical points of government subsidies on the formation of the green dairy industry chain.

the formation of green dairy industry chain, and help the green dairy industry chain system to reach an ideal equilibrium state.

\subsection{The Impact of Government Punishment on the Formation} of Green Dairy Industry Chain. When the government intends to promote the formation of green industry chain by means of punishment, it can be obtained from the evolutionary game power system that if the initial cooperation intention between the dairy farmers and dairy enterprises is strong as $x=y=0.9$, the critical point for dairy farmers on government punishment is $g_{1}=(93 / 80)$ and the critical 
point on dairy enterprises is $g_{2}=(3 / 80)$, which means when the government punishment is higher than the critical point, the dairy farmers and dairy companies will choose cooperative strategy for fear of excessive punishment on noncooperation. Likewise, if the government only implements punishment policy for the formation of the green industry chain, there is only one critical point. Assuming that punishment from the government is $g_{1}=1$ and $g_{2}=1.8$, farmers and dairy companies will maximize their own interests, and their selection strategy in the learning process of evolutionary game fluctuates between $(0,1)$, resulting in the fact that both sides cannot reach a stable equilibrium state (as shown in Figure 3). In the process of the game during 500 unit of time, the influence of contrast Figures 2 and 3 shows that the situation exists that the learning speed of the players below the critical points of the government rewards is far from higher than that with government punishment. This shows that the sensitivity of the influence of learning speed over government rewards is much higher than that over government punishment. Of course, it also related to dairy farmers and milk enterprise initial cooperation will.

Only when the government for dairy farmers and dairy enterprises punishment is greater than the critical point, $g_{1}=g_{2}=2.5$, dairy farmer and dairy companies will choose green production strategy. At this time, the dairy farmers and dairy enterprises would rather take the initiative to conduct green production than get heavy punishment. It is also the results of the final selection through continuous learning process, as shown in Figure 4. Therefore, it can be concluded that, in the absence of government subsidies, increasing government punishment can also effectively promote the green production of dairy farmers and dairy enterprises, promote the formation of the green dairy industry chain, and help the green dairy industry chain system to reach an ideal equilibrium state. It should be noted that the government's punishment is a mandatory measure, which may reduce the enthusiasm of dairy farmers and dairy enterprises to participate in the formation of the dairy industry chain and force them out of the industry.

\subsection{The Impact of Government Subsidies and Penalties on the} Formation of Green Dairy Industry Chain. Based on the analysis on (1) and (2), government subsidies and government punishment promote the evolutionary game equilibrium function (as shown in Figure 5). Obviously, the combination of government subsidies and government punishment will accelerate the game when the formation of ESS. When dairy farmers and dairy enterprises choose green production strategy, the government will give subsidies, and the opportunity cost will be exempted from government punishment. When the opportunity cost of subsidies and punishment is greater than the net gain without cooperation, both sides will avoid their own losses and choose cooperation.

Of course, the convergence speed of evolution game equilibrium solution for dairy farmers and dairy enterprises is different. That is to say, increasing the government subsidy by one unit or increasing the government punishment by one unit or both will speed up the cooperation between the

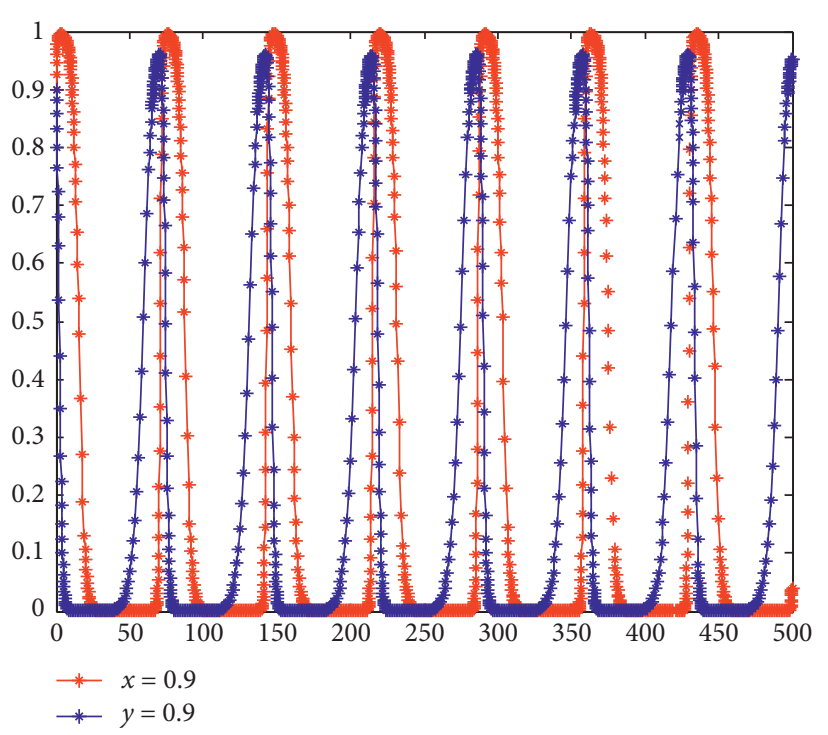

FIGURE 3: Influence of critical point of government punishment on the formation of green dairy industry chain.

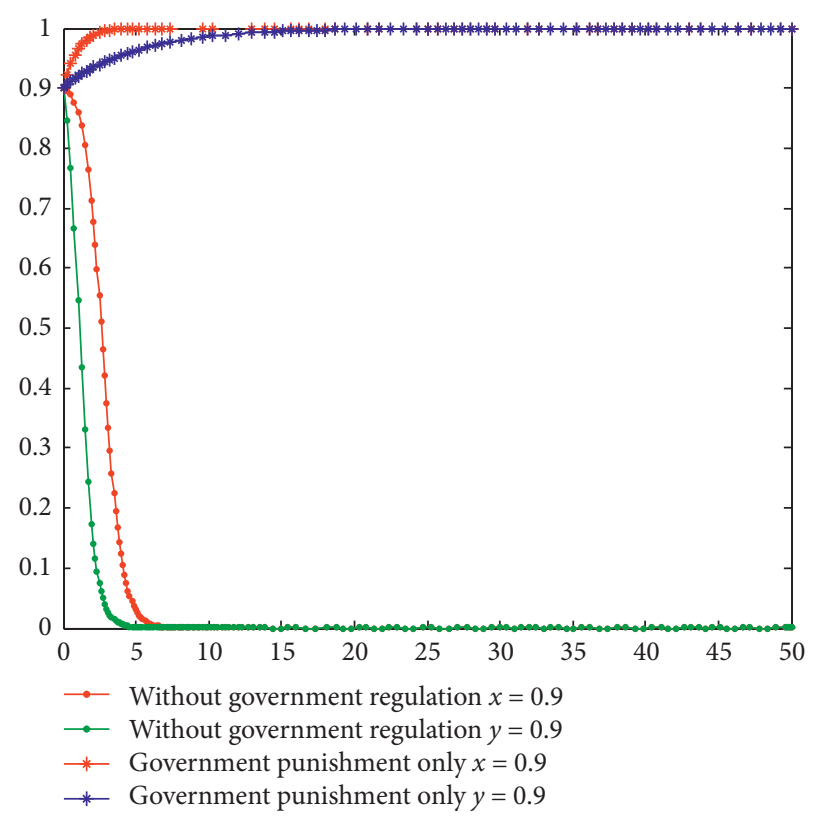

FIGURE 4: Influence of government punishment on the formation of the green dairy industry chain.

two parties. As shown in Figure 6, coexisting of government subsidy and government punishment has bigger promoting effect than only with government subsidy or with punishment, and the subsidy has more significant influence than the punishment. It is most effective when there are both government subsidies and government punishments. Cooperation can also be promoted when there are only government subsidies and government punishments, but subsidies and punishments must be strengthened.

5.4. The Influence of Green Production Cost on the Formation of Green Dairy Industry Chain. Green production cost is also 


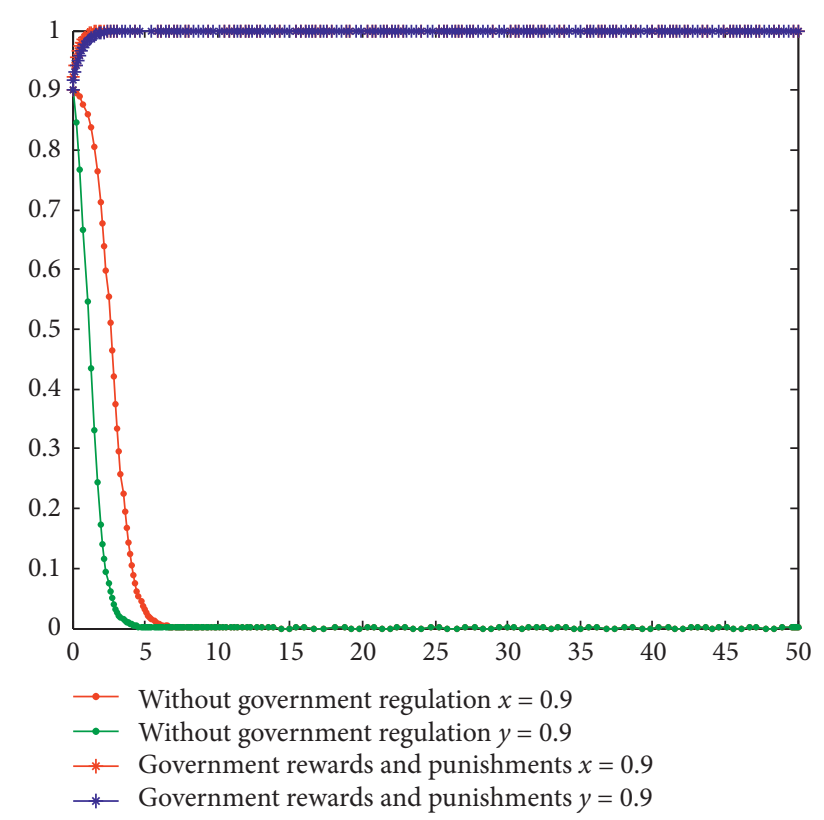

FIGURE 5: Influence of government subsidy and punishment on the formation of green dairy industry chain.

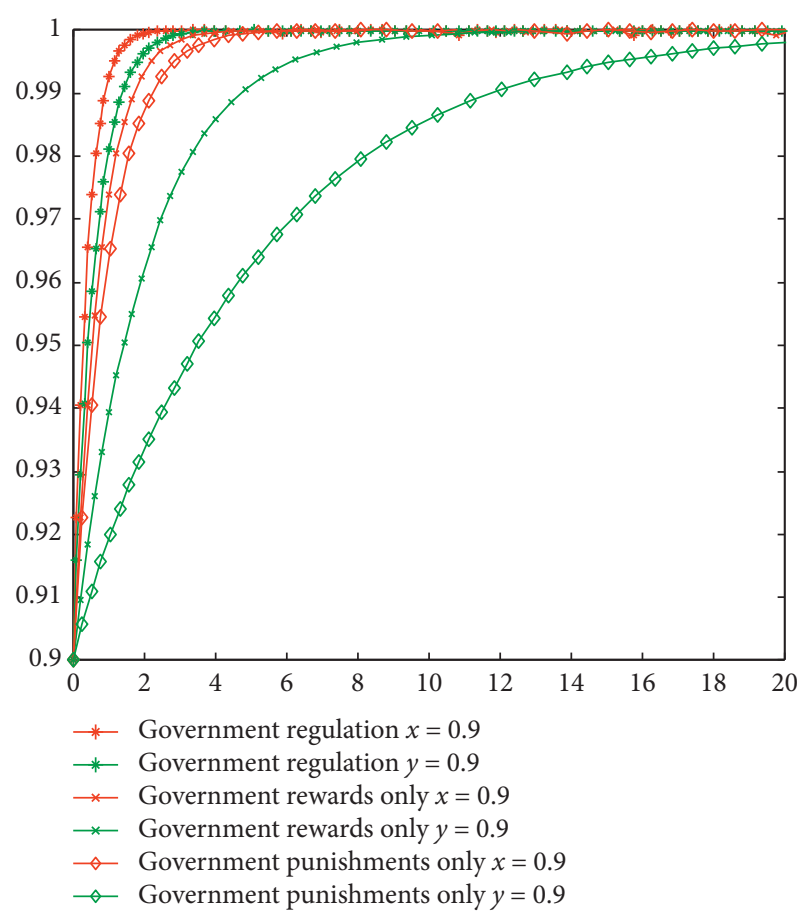

Figure 6: Comparison of convergence speed of government subsidies and punishments on the game between dairy farmers and dairy enterprises.

extremely important for the formation of the green dairy industry chain. In fact, the reduction of green production cost will eventually improve the net income of dairy farmers and dairy enterprises. In accordance with the evolutionary game power system, if the cooperation intention of both sides is as strong as $x=y=0.9$, the crucial point of green

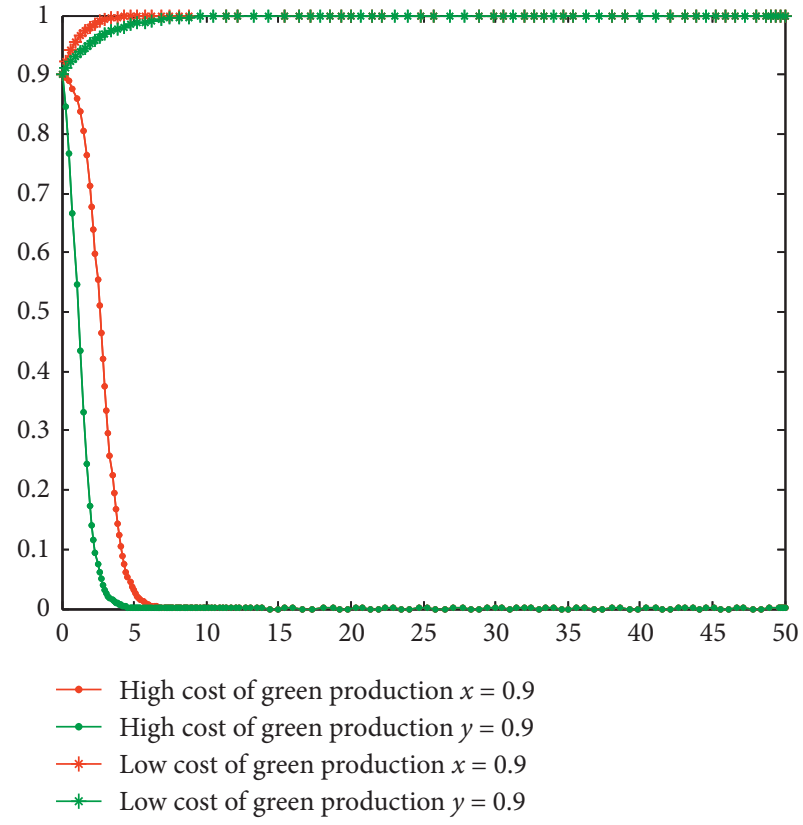

Figure 7: Influence of green production cost on the formation of green dairy industry chain.

production costs on dairy farmers is $\Delta C_{1}=1.35$, and on dairy enterprises is $\Delta C_{2}=1$ and $\Delta C_{2}^{\prime}=1.5$. In other words, when the production cost is higher than the critical point, dairy farmers and dairy enterprises will choose noncooperative strategy for the high cost and deficit of net income. The cooperation between dairy farmers and dairy enterprises can only be promoted by scientific and technological innovation through government training and green production cost reduction. When the green production cost is reduced through technical means and scientific and technological innovation, it is assumed that $\Delta C_{1}=0.5, \Delta C_{2}=0.3$, and $\Delta C_{2}^{\prime}=1$, and the initial intention of cooperation between dairy farmers and dairy enterprises is $x=y=0.9$, both sides of the game will obtain higher net benefits through green production and finally choose cooperation (as shown in Figure 7). Therefore, the reduction of green production cost is also an important factor to promote the formation of the green dairy industry chain, which can promote the green dairy industry chain system to reach an ideal equilibrium state.

\section{Conclusion}

Based on the basic theory of evolutionary game, this paper analyzed the forming mechanism of the green dairy industry chain under government supervision. The results showed that when dairy farmers and dairy enterprises have a strong desire to build a green dairy industry chain, if the cost of green production invested by dairy farmers and dairy enterprises does not get a large profit, both sides of the game will give up cooperation. When there is no government supervision, or the government supervision is not enough, the evolutionary game between dairy farmers and dairy enterprises is either uncooperative or changes periodically, which cannot achieve the effect of cooperation. Therefore, in 
the process of forming the green dairy industry chain, the government's supervision is extremely urgent. Under the condition of strict government supervision, government subsidies and punishments can greatly promote the formation of green dairy industry chain. The more government subsidies are, the more serious the government punishments will be and the less likely dairy farmers and dairy enterprises will choose the behavior strategy of nongreen production. Of course, promoting technological innovation and reducing green production costs through government training are also important means to promote bilateral cooperation. Therefore, establishing a government-led supervision mechanism, appropriately increasing subsidies, strengthening penalties, and reducing green production costs can effectively improve the cooperation between dairy farmers and dairy enterprises, so as to ensure the formation of a green dairy industry chain and protect the interests of the public.

Based on the abovementioned conclusions and analysis, the following suggestions are proposed for the formation of the green dairy industry chain.

Firstly, the government should reasonably formulate the reward and punishment system for the green dairy industry chain. In the process of promoting the formation of the green dairy industry chain, the government should consider various constraints, weigh the interests of all parties on the industrial chain, and formulate a reward and punishment system conducive to the formation of green dairy industry chain. Of course, this means that the government not only needs to pay more administrative costs in supervision but also needs to invest more incentive costs. Therefore, the government can develop a scientific and reasonable thirdparty supervision system to effectively supervise dairy farmers and dairy enterprises.

Secondly, reduce the cost of green production for dairy farmers and dairy companies. The government can provide basic training for dairy farmers and dairy enterprises so that they can acquire necessary green production skills and improve their overall production quality. At the same time, it is also possible to make use of the technological advantages of universities and research institutes to carry out technical research on green production through industry-universityresearch, so as to solve the technical problems existing in the process of green production. At the same time, the government can also equip dairy farmers and dairy companies with advanced green production testing equipment to reduce their production costs.

Thirdly, dairy products enterprises should establish a green development strategic plan. In addition to constantly innovating the design and development of dairy products, it is also necessary to use the green dairy product standard as a guideline to meet consumer demand for safe and high-quality dairy products. In terms of operation, we need to improve the control of dairy products processing and sales and improve the level of green and sustainable development of the company.

\section{Data Availability}

The data used to support the findings of this study are available from the corresponding author upon request.

\section{Conflicts of Interest}

The authors declare no conflicts of interest.

\section{Acknowledgments}

This work was supported by the National Natural Science Foundation of China (Project no. 71874184) and Xinjiang Tianshan army reclamation co., Ltd. (Project no. 2019ZH04). The funders had no role in the design of the study; in the collection, analyses, or interpretation of data; in the writing of the manuscript; or in the decision to publish the results.

\section{References}

[1] G. Tognon, L. M. Nilsson, D. Shungin, L. Lissner, J. H. Jansson et al., "Nonfermented milk and other dairy products: associations with all-cause mortality," The American Journal of Clinical Nutrition, vol. 105, 2017.

[2] J. M. G. Lankveld, "Quality, safety and value optimization of the milk supply chain in rapidity evolving central and Eastern European markets," Leerstoelgroep Productontwerpen en Kwaliteskunde, vol. 9, p. 14, 2004.

[3] H. Dornon, Guide to Good Dairy Farming Practices 2004, Introduction FAOIDF, Paris, France, 2006.

[4] C. S. Cardoso, M. A. Keyserlingk, M. J. Hotzel et al., "Trading of animal welfare and production goals: Brazilian dairy farmers' perspectives on calf dehorning," Livestock Science, vol. 187, no. 2, pp. 102-108, 2016.

[5] T. Koca, M. Akcam, F. Serdaroglu et al., "Breakfast habits, dairy product consumption, physical activity, and their associations with body mass index in children aged 6-18," European Journal of Pediatrics, vol. 176, no. 9, pp. 1251-1257, 2017.

[6] U. Sorge, D. Kelton, K. Lissemore et al., "Attitudes of Canadian dairy farmers toward a voluntary Johne's disease control program," Journal of Dairy Science, vol. 93, no. 4, pp. 0-1499, 2010.

[7] Q. Liu, C.. Yi, and Z. Y. Dai, "Application of control chart in quality control of dairy enterprises," Journal of Food Safety and Quality Inspection, vol. 9, no. 21, pp. 240-248, 2018.

[8] Q. Wu, Y. Y. Zhang, and S. M. Sun, "Analysis on the behavior of total quality control of dairy farmers based on Logit-ISM model," Journal of Agrotechnical Economics, vol. 2017, no. 3, pp. 55-65, 2017.

[9] X. X. Zhang and X. J. Gong, "Research progress of dairy product safety based on industrial chain optimization," Journal of Dairy Science and Technology, vol. 40, no. 3, pp. 24-28, 2017.

[10] B. Stefansdottir and M. Grunow, "Selecting new product designs and processing technologies under uncertainty: twostage stochastic model and application to a food supply chain," International Journal of Production Economics, vol. 201, pp. 89-101, 2018.

[11] L. Dries, E. Germenji, N. Noev, and J. F. Swinnen, "Farmers, vertical coordination, and the restructuring of dairy supply chains in Central and Eastern Europe," World Development, vol. 37, no. 11, pp. 1742-1758, 2009.

[12] H. Ding, Y. Fu, L. Zheng, and Z. Yan, "Determinants of the competitive advantage of dairy supply chains: evidence from the Chinese dairy industry," International Journal of Production Economics, vol. 209, pp. 360-373, 2019. 
[13] S. Nyokabi, S. J. Oosting, B. O. Bebe et al., "The Kenyan dairy sector: stakeholder roles and relationships, and their impact on milk quality," in Farming Systems: Facing Uncertainties and Enhancing Opportunities, Wageningen University \& Research, Wageningen, Netherlands, 2018.

[14] C. Kilelu, L. Klerkx, A. Omore, I. Baltenweck, C. Leeuwis, and J. Githinji, "Value chain upgrading and the inclusion of smallholders in markets: reflections on contributions of multi-stakeholder processes in dairy development in Tanzania," The European Journal of Development Research, vol. 29, no. 5, pp. 1102-1121, 2017.

[15] M. Gorton, R. Angell, L. Dries, V. Urutyan, E. Jackson, and J. White, "Power, buyer trustworthiness and supplier performance: evidence from the Armenian dairy sector," Industrial Marketing Management, vol. 50, pp. 69-77, 2015.

[16] S. A. Yawar and K. Kauppi, "Understanding the adoption of socially responsible supplier development practices using institutional theory: dairy supply chains in India," Journal of Purchasing and Supply Management, vol. 24, no. 2, pp. 164176, 2018.

[17] T. Goesch, K. Lawson, R. Green, and K. Morey, Australia's Beef Supply Chains Infrastructure Issues and Implications, ABARES Research Report 15.7, ABARES, Canberra, Australia, 2015.

[18] E. G. Kirilova and N. G. Vaklieva-Bancheva, "Environmentally friendly management of dairy supply chain for designing a green products' portfolio," Journal of Cleaner Production, vol. 167, pp. 493-504, 2017.

[19] D. Powell, S. Lundeby, L. Chabada, and H. Dreyer, "Lean Six Sigma and environmental sustainability: the case of a Norwegian dairy producer," International Journal of Lean Six Sigma, vol. 8, no. 1, pp. 53-64, 2017.

[20] W. McWilliam and M. Balzarova, "The role of dairy company policies in support of farm green infrastructure in the absence of government stewardship payments," Land Use Policy, vol. 68, pp. 671-680, 2017.

[21] M. Yazdani, P. Chatterjee, E. K. Zavadskas, and S. H. Zolfani, "Integrated QFD-MCDM framework for green supplier selection," Journal of Cleaner Production, vol. 142, pp. 37283740, 2017.

[22] A. Rajabian Tabesh, P. J. Batt, and B. Butler, "Modelling the impact of environmental and organizational determinants on green supply chain innovation and performance," Journal of Food Products Marketing, vol. 22, no. 4, pp. 436-454, 2016.

[23] J. C. V. Martínez and J. C. Fransoo, "Green facility location," in Sustainable Supply Chains, pp. 219-234, Springer, Berlin, Germany, 2017.

[24] K. T. Shibin, A. Gunasekaran, T. Papadopoulos, R. Dubey, M. Singh, and S. F. Wamba, "Enablers and barriers of flexible green supply chain management: a total interpretive structural modeling approach," Global Journal of Flexible Systems Management, vol. 17, no. 2, pp. 171-188, 2016.

[25] M. P. Squicciarini, A. Vandeplas, E. Janssen, and J. Swinnen, "Supply chains and economic development: insights from the Indian dairy sector," Food Policy, vol. 68, pp. 128-142, 2017.

[26] S. Yildiz Çankaya and B. Sezen, "Effects of green supply chain management practices on sustainability performance," Journal of Manufacturing Technology Management, vol. 30, no. 1, pp. $98-121,2019$.

[27] J. W. Friedman, Game theory with applications to economics, Oxford University Press, Oxford, UK, 1986.

[28] R. B. Myerson, Game Theory, Harvard University Press, Cambridge, MA, USA, 2013.
[29] C. F. Camerer, Behavioral Game Theory: Experiments in Strategic Interaction, Princeton University Press, Princeton, NJ, USA, 2011.

[30] J. W. Weibull, Evolutionary Game Theory, MIT press, Cambridge, MA, USA, 1997.

[31] K. E. Boulding, Evolutionary Economics, Sage Publications, New York, NY, USA, 1981.

[32] D. Friedman, "On economic applications of evolutionary game theory," Journal of Evolutionary Economics, vol. 8, no. 1, pp. 15-43, 1998.

[33] P. Ji, X. Ma, and G. Li, "Developing green purchasing relationships for the manufacturing industry: an evolutionary game theory perspective," International Journal of Production Economics, vol. 166, pp. 155-162, 2015.

[34] A. Abedullah, N. Mtimet, N. Teufel, M. N. Ibrahim, Z. Mustafa, and A. Ahmad, Dairy value chains in Pakistan Stakeholders' Involvement and Constraints Analysis, vol. 9, p. 14, 2015.

[35] A. Criscuolo and F. Cuomo, Market Opportunities for Green Upgrading and Innovation: Sustainability Demand Analysis for the Beef, Soy, Dairy and Tourism Industries, Chandigarh, India, 2018.

[36] C. W. Kilelu, L. Klerkx, and C. Leeuwis, "Supporting smallholder commercialisation by enhancing integrated coordination in agrifood value chains: experiences with dairy hubs in Kenya," Experimental Agriculture, vol. 53, no. 2, pp. 269-287, 2017.

[37] S. B. Tsai, B. Liu, and Y. Li, Eds., Green Production Strategies For Sustainability, IGI Global, PA, USA, 2017. 